10 Eisen A, Bertrand G. Isolated accessory nerve palsy of spontaneous origin. Arch Neurol 1972;27:496-502.

11 Krogness K. Serial conduction studies of the spinal accessory nerve used as a prognostic tool in a lesion caused by lymph node biopsy. Acta Chir Scand 1974;140:7-11.

12 Petrera JE, Trojaborg W. Conduction studies along the accessory nerve and follow-up of patients with trapezius palsy. $J$ Neurol Neurosurg Psychiatry 1984;47:630-6.

Accepted 26 March 1987

\section{Smoking and dementia of Alzheimer type}

Sir: Several surveys have reported a negative association between smoking habits and Parkinson's disease suggesting that smoking may decrease an individual's risk of developing the condition. ${ }^{12}$ An observation made by Appel, ${ }^{3}$ that only six of 30 Alzheimer patients in his study had smoked at any time in their lives, led him to conclude that a similar effect may operate in dementia of Alzheimer type (DAT). This is of interest in view of the recently demonstrated loss of nicotinic receptors in the cerebral cortex of DAT patients. ${ }^{4}$

Conversely, Shalat ${ }^{5}$ has presented data from a case control study, showing that Alzheimer patients were more than twice as likely to be smokers or ex-smokers than were controls. Furthermore, ${ }^{6}$ increased risk of the disease was positively correlated with level of cigarette consumption.

Our data refer to patients attending the Maudsley Memory Clinic and the psychogeriatric unit of the Royal Bethlem and Maudsley Hospitals. The medical notes of 81 persons over the age of 65 with a diagnosis of "probable" dementia of Alzheimer type $^{7}$ were reviewed to obtain information about smoking habits. Where such information was not recorded the next of kin were contacted by telephone. One hundred and twelve persons from a local luncheon club and care home were selected as age-matched controls and interviewed.

Seventy one per cent of male DAT patients and $32 \%$ of female DAT patients either smoked or gave a history of having smoked, as compared with $77 \%$ of male controls and $44 \%$ of female controls. Even allowing for sex differences (with the use of an appropriate log-linear $\operatorname{model}^{8}$ ) no significant difference in the lifetime prevalence of smoking between the two groups was found $\left(\mathrm{chi}^{2}=1 \cdot 23, \mathrm{p}=0.75\right.$, Odd's ratio $=1 \cdot 58$ ).

Our results do not support either study referred to above but are in accord with the findings of an epidemiological study of patients developing the disease before the age of $70 .^{9}$

Clearly further studies are required to elucidate this question but can only be conducted if past and present smoking behaviour is perceived as an important variable and therefore accurately recorded in .medical notes.

GEMMA MM JONES MARGARET REITH MP PHILPOT

BARBARA J SAHAKIAN Section of Old Age Psychiatry, Institute of Psychiatry, De Crespigny Park, London SE5 8AF, UK

\section{References}

1 Baumann R, Jameson H, McKean H, Haack D, Weesburg L. Cigarette smoking and Parkinson's disease. 1. A comparison of cases with matched neighbours. Neurology 1980;30:839-43.

2 Godwin-Austen R, Lee P, Marmot M, Stern G. Smoking and Parkinson's disease. J Neurol Neurosurg Psychiatry 1982;45:577-81.

3 Appel S. Alzheimer's disease. In: Enna S, ed. Brain Neurotransmitters and receptors in aging and age-related disorders. New York: Raven Press, 1981:203-7.

4 Whitehouse P, Martino A, Antuono P, et al. Nicotinic acetylcholine binding sites in Alzheimer's disease. Brain Res 1986;371: 146-51.

5 Shalat S. A case control study of medical and familial history in Alzheimer's disease. Paper presented at the annual conference of the Society for Epidemiologic Research. (Pittsburgh, Penn, June 17-20, 1986).

6 Shalat S. Personal communication.

7 McKhann G, Drachman D, Folstein M, Katzman R, Price D, Stadlan EM. Clinical diagnosis of Alzheimer's disease: report of the NINCDS-ADRDA Work Group under the auspices of the Department of Health and Human Services Task Force on Alzheimer's disease. Neurology 1984;34:93944.

8 Dunn G. The role of linear models in psychiatric epidemiology. Psychol Med 1981;11:179-84.

9 Heyman A, Wilkinson W, Stafford J, Helms M, Sigmon A, Weinberg T. Alzheimer's disease: a study of epidemiological aspects. Ann Neurol 1984;15:335-41.

Accepted 16 April 1987
Listeria monocytogenes infection with rhombencephalitis

Sir: Listeria monocytogenes meningitis is not uncommon, ${ }^{12}$ but rhombencephalitis as a complication is rare, only six cases being reported in the English literature. ${ }^{3-8}$ We describe a further case which draws attention to impaired central control of respiratory movement during the acute illness and to the development of new brain stem lesions long after the disappearance of active infection.

A previously healthy 43 year old Caucasian male presented with nausea, abdominal pain and headache of $\mathbf{4}$ days' duration. Increasing unsteadiness of gait, slurring of speech and difficulty swallowing had been present for two days. On the day of admission he developed perioral numbness and left facial weakness. The temperature was $38^{\circ} \mathrm{C}$, pulse $100 \mathrm{bpm}$ and blood pressure $150 / 90 \mathrm{~mm} \mathrm{Hg}$. He was alert and orientated. The neck was supple. There was evidence for multifocal bilateral brainstem disease with dysarthria, right ptosis, pupillary asymmetry, left conjugate gaze paresis, left facial paralysis of lower motor neuron type, and weakness of the left palate and right side o the tongue. Pinprick and temperature sensa일 tion were impaired in a muzzle distributioæ extending down the right side from the face to the TII dermatome. There was dysmetria of the left arm and leg and gross truncal and gait ataxia.

A contrast enhanced CT brain scan an chest radiograph were normal. Cere brospinal fluid (CSF) contained 124 leukocytes $/ \mathrm{mm}^{3}(56 \%$ polymorphonuclears, $38 \%$ lymphocytes, $6 \%$ monocytes), the protein was $0.76 \mathrm{~g} / \mathrm{l}$, and glucose $5.5 \mathrm{mmol} / 1$. No organisms were present in the stained film or grew on culture.

He received intravenous fluids, ampicillin, cloxacillin and tobramycin. Five hours after admission, while awake, there was a rapid decrease in respiratory effort and he became cyanosed. He could take deep breaths on command but during a prolonged apnoeic episode a tonic-clonic seizure occurred. After recovery of consciousness automatic respiratory movement did not return and intermittent positive pressure ventilation (IPPV) was begun. On the following day Listeria monocytogenes was isolated from the blood cultures. Ampicillin and tobramycin were continued for four weeks.

The systemic evidence for infection settled over the first two days but there was further neurological deterioration with the development of complete right ptosis, right facial weakness, severe weakness of jaw opening and closure, paralysis of tongue protrusion

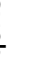


and slight subjective hearing impairment on the left. Tracheostomy was performed on the third hospital day and IPPV was continued for two weeks. During subsequent weaning from the respirator his breathing was maintained while awake, but during sleep there were frequent episodes of central apnoea with arterial oxygen saturation frequently dropping to $85 \%$.

Neurological improvement began two weeks after admission. At three months the major findings included continuing apnoeic episodes while asleep requiring nocturnal ventilation, complete left facial paralysis, markedly impaired swallowing, minor incoordination of the left arm and leg and mild unsteadiness of gait.

At the end of the fifth month there was development over five days of marked unsteadiness of gait, inco-ordination of the arms and increasing difficulty in swallowing. A CT brain scan and CSF examination were normal. Recovery to his previous state occurred over the next 6 weeks.

At the end of 8 months assisted respiration was no longer required during sleep and the tracheostomy had been closed. There were no significant changes during the next three years.

Somatosensory evoked potentials (SEPs) and brain stem auditory evoked potentials (BAEPs) were recorded during the acute illness and the recovery period using standard methods and normal values for this laboratory. ${ }^{9}$ On the second hospital day SEPs were normal but BAEPs following stimulation of the right ear showed slight prolongation of the Wave I-V interval. Nine days later SEPs remained normal but the BAEPs showed a further increase of the Wave I-V interval on the right and loss of all waves following Wave I on the left, despite stimulation at least 55 decibels above left ear hearing threshold. On hospital day 29, while the patient was recovering, the central somatosensory conduction time ${ }^{10}$ to the left hemisphere was relatively prolonged compared with that to the right. Subsequently the central conduction time to the right hemisphere became absolutely prolonged while that to the left remained unchanged. Although the BAEPs from the right ear returned to normal, those from the left beyond Wave I remained absent until recordings made at the time of deterioration in the 5th month, when they had returned but showed slight prolongation of the I-V interval. Thirty-two months after admission SEPs and BAEPs were normal.

This patient's presentation with a systemic prodromal illness followed by rapidly progressive multifocal signs in the brain stem was similar to those previously reported in the literature. As in most of these cases, the organism was isolated from blood cultures but not from the CSF. The loss of automatic respiratory movements (Ondine's curse) has not been described in previous patients with listeria rhombencephalitis, although "respiratory failure" has occurred in two. ${ }^{27}$ This unusual but important complication might be expected in patchy disease of the lower brain stem from involvement of central respiratory control centres.

The evoked potential studies in this patient showed several unexpected features. The disappearance of all BAEPs beyond Wave $I$ is consistent with a pontomedullary lesion; although this change with preservation of hearing may be seen in multiple sclerosis (unpublished observations) we have not observed it in any other neurological diseases. The later deterioration in the central somatosensory conduction time to the right hemisphere, occurring while the patient was recovering, suggested the development of a new subclinical brain stem lesion. Following this, another lesion in the brain stem-cerebellar connections occurred at five months causing inco-ordination and ataxia.

Little is known of the histopathology of listeria rhombencephalitis. Formation of multiple small abscesses with gram positive bacilli has been reported at necropsy ${ }^{16}$ and the evidence suggests that direct bacterial invasion occurs in the acute stage. There is an analogy in listeria infection of ruminants. ${ }^{1}$ However, in this patient an additional mechanism must have been present with the appearance of clinical and subclinical lesions long after resolution of the infection. The pattern of disease raises the possibility of recurrent episodes of brain stem demyelination as a remote, postinfectious complication of Listeria monocytogenes infection of the central nervous system.

\section{RICHARD W FRITH* $\dagger$ PETER R BUCHANAN $\ddagger$ GAVIN L GLASGOW* Departments of Neurology,* Clinical Neurophysiology $\dagger$ and Critical Care, $\ddagger$ Auckland Hospital Park Road, Auckland, New Zealand}

\section{References}

1 Heck AF. Listeria monocytogenes. In: Vinken PJ, Bruyn GW, eds. Handbook of Clinical Neurology. Amsterdam: Elsevier/NorthHolland Biomedical Press, 1978. Volume 33.
2 Nieman RE, Lorber B. Listeriosis in adults: 을 changing pattern. Rev Inf Dis 1980;2:207-27

3 Duffy PE, Sassin JF, Summers DS, Lourie HC Rhombencephalitis due to Listeria mono cytogenes. Neurology 1964;14:1067-72.

4 Ford PM, Herzberg L, Ford SE. Listeria mone cytogenes: six cases affecting the central ner= vous system. $Q J$ Med 1968;37:281-90.

5 Katz RI, McGlamery ME, Levy R. CNS listeriosis. Arch Neurol 1979;36:513-4.

6 Kennard C, Howard AJ, Scholtz C, Swash M Infection of the brain stem by Listeria monor. cytogenes. J Neurol Neurosurg Psychiatr 1979;42:931-3.

7 Mahoney JF, Tambyah JA, Dalton VC, et ato Pontomedullary listeriosis in renal allografe recipient. Br Med J 1974;2:705.

8 Weinstein AJ, Schiavone WA, Furlan AJ Listeria rhombencephalitis. Arch Neurog 1982;39:514-6.

9 Cant BR, Hume AL, Judson JA, Shaw NA The assessment of severe head injury b $\vec{b}$ short-latency somatosensory and brain-stem auditory evoked potentials. Electroenceph $-\overrightarrow{\mathrm{C}}$ alogr Clin Neurophysiol 1986;65:188-95. oै

10 Hume AL, Cant BR. Central conduction tims in central somatosensory pathways in man? Electroencephalogr Clin Neurophysiol 1978 45:361-75.

Accepted 25 April 1987

Asymmetry of pathology in Alzheimerr's disease

Sir: For much recent work on new్̄ं transmitter abnormalities in Alzheim? disease it has been the practice in manyo centres to fix one cerebral hemisphere for histological study and to freeze the other fop neurochemical investigation. The assump tion underlying this is that the disease pro cess affects the brain symmetrically, allowe ing correlation to be made betwee histological changes on one side and cheme ical changes on the other. This assumptio $\overrightarrow{\vec{B}}$ has been called into question in a recen $\$$ study by Arendt et al. ${ }^{1}$ These authors reported cell counts in the nucleus basalio and plaque counts in the cortex on bot sides of the brain in cases of Alzheimer's dis ease. They found, in some cases, "marke differences in regional plaque count between the two hemispheres". The differences in the mean counts for the hemio spheres did not reach statistical significance however. Nevertheless, we felt that the doubt cast on the current practice of dividing the brain sagittally called for review of other data in the literature and small additional study designed to addresస్ 